\title{
Cultura como prática de cidadania: uma perspectiva ampliada do conceito
}

\author{
Culture as a practice of citizenship: a larger perspective of the concept
}

\section{Aretha Bley Pestana *}

\begin{abstract}
Resumo:
O objetivo deste artigo é contribuir, de maneira geral, para a desconstrução da visão de cultura como mera mercadoria e, que por isso, é tratada, via de regra, como suplementar no conjunto das políticas públicas, reduzida quase sempre à noção de lazer, diversão e supérfluo. Partimos da idéia de que a cultura está presente em todos os aspectos da vida da sociedade. A pesquisa bibliográfica aponta para uma nova perspectiva, aquela que entende o exercício da cidadania a partir da manifestação cultural e a cultura não como isolada do todo social, mas como direito de todos os cidadãos.
\end{abstract}

Palavras-chave: Cultura. Direitos. Políticas públicas. Cidadania.

\begin{abstract}
:
The purpose of this article is to contribute, in general, for the deconstruction of the understanding of culture as a simple object and therefore, via all rules, treated as an accessory of the parties of public policies, almost always reduced as an understanding of leisure, fun and superfluous. We come from the idea that the culture is introduced in all aspects of the life of the society. The bibliographic research points out to a new perspective, that considerate the prosecution of the citizenship from the cultural manifest and the culture not as isolated from the whole society, but as right for all citizens.
\end{abstract}

Keywords: Culture. Rights. Public policies. Citizenship.

"A gente não quer só comida A gente quer comida, diversão e arte.

[...] A gente não quer só dinheiro, A gente quer dinheiro e felicidade." Comida, Marcelo Fromer, Arnaldo Antunes, Sérgio Britto

\footnotetext{
* Graduada em Serviço Social pela UniFMU e em Letras pela USP; Assistente Social do Instituto Israelita de Responsabilidade Social Albert Einstein. E-mail: arethabley@hotmail.com
} 


\section{Introdução}

Iniciamos este estudo com a idéia de que, para pensar a sociedade, é fundamental que as manifestações culturais sejam consideradas como expressão das vivências das pessoas em determinados espaços. Por conseguinte, pensar uma análise tomando por base que o fator cultural de um local pode resultar em um olhar específico em relação a sua dinâmica social.

A cultura, portanto, é aqui entendida como todo processo humano que se constrói na prática social. Além disso, como destaca o artigo 215 da Constituição Federal e o artigo 27 da Declaração dos Direitos Humanos, a cultura é reconhecida como um direito de todos os cidadãos.

Partimos do pressuposto de que o cultivo e a valorização da cultura podem auxiliar na busca de formas para a promoção do exercício da cidadania a partir das manifestações e expressões culturais populares. E, ainda, que o alargamento da concepção de cultura pode contribuir na elaboração de políticas públicas que promovam a inclusão social, além de reconhecer a diversidade cultural constituída histórica e socialmente.

Para desenvolvermos o objetivo de compreender a cultura para além do lazer ou da mercadoria, a metodologia utilizada abrangeu criteriosa revisão bibliográfica, recorrendo a obras que viabilizassem referências sobre definição e interpretação de cultura, cultura popular, cidadania e políticas públicas. Adotamos o caminho metodológico da abordagem qualitativa, lembrando que não utilizamos a bibliografia e os dados como comprovação de verdade previamente estabelecida, mas como fonte de inspiração para o debate conceitual.

\section{Cultura: civilização, raça e etnia}

No sentido etimológico da palavra, de acordo com Chauí (1996, 2006), cultura deriva do latim colere, empregada com o significado de cultivo e cuidado com a terra, as plantas e os animais, por isso agricultura. Significa também o cuidado com a educação e as crianças, então puericultura. E, ainda, expressa o cuidado com os deuses, donde a idéia de culto. Fundamentalmente, cultura trata da relação do homem com a natureza, educação e religiosidade. 
No século XVIII, quando do lluminismo europeu, o conceito passa a vincular-se ao de civilização. Tem início, então, a oposição entre natureza e cultura.

Para Choay (1999), a palavra civilização resulta daquilo que os romanos chamavam de civitas ou civis. Segundo a autora, civitas significava "[...] comunidade de cidadãos que habitam a cidade" e, assim, equivalia à idéia de polis presente na Grécia Clássica, ou seja, "dimensão simbólica com características moral, política e religiosa, ligada ao ideário de cidadão" (CHOAY, 1999, p. 69).

Todavia, é importante destacarmos que, para os gregos e romanos, nem todos os que moravam na cidade eram cidadãos. Somente os que poderiam decidir os rumos da cidade usufruíam o direito de cidadania e, como conseqüência, de civita/polis. À margem da categoria de cidadãos, estavam mulheres, crianças, adolescentes, estrangeiros e escravos.

Conforme Chauí (2006), muitos dos pensadores iluministas do século XVIII, ao relacionarem cultura à idéia de civilização (civitas), mantiveram a visão seletiva e hierárquica presente entre os romanos e gregos. Neste sentido, enfatiza a autora, cultura é entendida como:

[...] o padrão ou o critério que mede o grau de civilização de uma sociedade. Assim, a cultura passa a ser encarada como um conjunto de práticas (artes, ciências, técnicas, filosofias, ofícios) que permite avaliar e hierarquizar as sociedades, segundo um critério de evolução. No conceito de cultura, introduz-se a idéia de tempo, mas de um tempo muito preciso, isto é, contínuo, linear e evolutivo, de tal modo que, pouco a pouco, cultura torna-se sinônimo de progresso. Avalia-se o progresso de uma civilização pela sua cultura e avalia-se a cultura pelo progresso que ela traz a uma civilização (CHAUI, 2006, p.130).

O conceito iluminista de cultura refere-se ao aprimoramento racional e moral, tendo a civilização européia capitalista como modelo para definir superioridade e inferioridade social, cultural, econômica e política. Concepção de cultura que reforça, por conseguinte, as modalidades de imposições que sustentam as relações de dominação e subordinação, dentre elas, a divisão da sociedade entre ricos e pobres e a reprodução do ideário de que existem sociedades e indivíduos cultos e incultos ou civilizados e não civilizados.

Explica Chauí (2006, p. 106) que: 
Culta era a pessoa moralmente virtuosa, politicamente consciente e participante, intelectualmente desenvolvida pelo conhecimento das ciências, das artes e da filosofia, de sorte que a divisão social das classes era sobredeterminada pela distinção entre cultos (os senhores) e incultos (escravos, servos e homens livres pobres), e a distinção entre os povos se fazia pela designação do outro como bárbaro.

No Dicionário Houaiss da Língua Portuguesa (2011), lemos que civilização é o "conjunto de aspectos peculiares à vida intelectual, artística, moral e material de uma época, de uma região, de um país ou de uma sociedade" e, também, "processo histórico de evolução social e cultural". Definições que nos permitem perceber, ainda hoje, a utilização da palavra para denominar manifestações artísticas, acadêmicas e eruditas, ocultando, assim, a diversidade de possibilidades presentes no conceito.

Embora haja variações da ideia de cultura, de acordo com Cuche (2002, p. 109) “[...] encontramo-nos atualmente diante de um paradoxo: enquanto o conceito de cultura é reexaminado de maneira crítica nas ciências sociais, [...] este mesmo conceito conhece uma difusão notável nos mais diversos meios sociais e profissionais", reiterando, em muitos casos, posições etnocêntricas, racistas e preconceituosas no sentido conceitual e do senso comum.

Outra possibilidade do estudo do conceito de cultura está na sua relação com o de raça. Como explica Schwarcz, a palavra raça, inicialmente, tomou como base, para o entendimento dos homens e das sociedades, as diferenças biológicas e físicas como hereditariedade, ascendência genealógica e cor da pele.

Exemplo disso foram as classificações raciais, como as feitas pelo Conde francês Gobineau em seu Ensaio sobre a desigualdade das raças humanas. Classificou a raça branca como superior em relação às raças negra e amarela e afirmou que "[...] misturar sangue é uma fonte de degeneração" (apud KARL, 1995, p. 134).

Nos séculos XIX e XX, realizavam-se estudos como os de frenologia, craniologia $^{1}$ e anatomia com o intuito de construir "tipos e raças puras", uma vez que se condenava a

\footnotetext{
${ }^{1}$ Segundo o Dicionário Houaiss da Língua Portuguesa (2011), "frenologia é a doutrina segundo a qual cada faculdade mental se localiza em uma parte do córtex cerebral e o tamanho de cada parte é diretamente proporcional ao desenvolvimento da faculdade"; e "craniologia é o estudo comparativo das diferentes formas de crânios humanos". Site identificado nas referências bibliográficas.
} 
hibridação humana, em função de uma suposta esterilidade das "espécies miscigenadas" (SCHWARCZ, 1993, p. 47, 54).

No século XIX, autores como Francis Galton criaram termos para defender a imutabilidade e a pureza racial, como a palavra eugenia (uma das bases das práticas raciais nazistas no século XX). Outros teóricos utilizavam concepções do evolucionismo e darwinismo social para hierarquizar raças, como fizeram Quatrefage e Agassiz, Morton, Spencer. Existiram, também, aqueles que se baseavam nas determinações geográficas como fatores determinantes para o entendimento das diferenças raciais e culturais como Ratzel e Buckle.

Conforme Hobsbawm (1995), as concepções raciais serviram para justificar o domínio de determinados povos sobre outros e, segundo Foucault (1985), como uma das formas de poder. Teorias estas que permanecem no século XXI, buscando identificar e justificar desigualdades sociais e econômicas.

Porém, apesar das tentativas de superar o conceito de raça, negando sua validade científica e apresentando o conceito de etnia, tanto a concepção iluminista de cultura quanto as teorias raciais ganharam novas cores. Conforme Cuche (2002), isto ocorreu como derivação da relação do conceito de cultura com o de etnia, sem superar a noção de superioridade e inferioridade. Posições presentes em conjuntos teóricos como o evolucionismo e o neo-evolucionismo. ${ }^{2}$

É possível afirmar que muitos dos parâmetros dessas concepções etnocêntricas ${ }^{3}$ estão presentes ainda hoje, com diferenciações e variações. Ou seja, é comum encontrarmos no debate e nas descrições culturais o viés evolucionista, neoevolucionista e, ainda, iluminista e racista.

Utilizaremos, novamente, a definição do Dicionário Houaiss da Língua Portuguesa, por possibilitar a percepção do uso formal e informal do termo etnia em relação à palavra cultura. Segundo o léxico, etnia seria a "[...] coletividade de indivíduos que se diferencia por sua especificidade sociocultural, refletida principalmente na língua, religião e

\footnotetext{
${ }^{2}$ No evolucionismo, citamos Spencer, Maine e Tylor, No neoevolucionismo, Leslie A. White e Gordon Childe. ${ }^{3}$ O termo deriva da palavra etnocentrismo que, segundo o Dicionário Houaiss significa, "[...] visão de mundo característica de quem considera o seu grupo étnico, nação ou nacionalidade socialmente mais importante do que os demais". Site identificado nas referências bibliográficas.
} 
maneiras de agir". Definição que aceitamos e aplicamos neste estudo por possibilitar a percepção da diversidade, sem desconsiderar o todo social.

Entretanto, salienta que o vocábulo etnia também é empregado como "[...] base biológica, podendo ser definida por uma raça, uma cultura ou ambas". Assim, por vezes, o uso da palavra etnia legitima a existência de cultura, civilização e raça superior. Refutamos esta leitura por entendermos que diferença cultural e étnica não significa superioridade e inferioridade racial e civilizacional.

Nas últimas três décadas do século XX, segundo Gohn (2005, p. 41), “[...] o tema da cultura foi o grande elemento revitalizador do pensamento nas Ciências Humanas, responsável pelo resgate de teorias e autores, ressignificação das práticas sociais e criação de novos paradigmas para analisar e interpretar a realidade social".

\section{Cultura como todas as manifestações do homem}

Conhecer as diversas expressões do cotidiano ${ }^{4}$, assim como percebê-lo como uma categoria que contempla elementos da estrutura social e do próprio indivíduo, é fundamental para pensarmos os sentidos de cultura. Para Paulo Netto e Carvalho (1989):

A cotidianidade contém alguns aspectos fundamentais para a constituição cultural. Ela é o cenário das experiências materiais, concretas e também da construção da subjetividade, das emoções, comportamentos e representações. Como concepção totalizante da vida cotidiana como centro do sistema de comunicação e informação entre os indivíduos, a cotidianidade é o lugar onde se podem encontrar as possibilidades transformadoras da sociedade (apud FERREIRA, 1997, p. 41).

Pensamos a cultura não como um elemento exterior à sociedade, de modo a completá-la, tampouco reduzida às manifestações artísticas, embora seja esta uma de suas dimensões, ou apenas como representação de determinado período histórico ou sociedade, mas sim como todas as manifestações dos homens relativas à práxis social. Trata-se de um processo que se constrói na prática social; “[...] o conjunto de processos

\footnotetext{
${ }^{4}$ Embora o conceito de cotidiano esteja presente desde a Grécia Antiga, sua tematização ganha destaque em 1946 com Lefèbvre na França. Outros autores fundamentais na discussão do cotidiano em sua relação com a cultura são: E. P. Thompson e Michel de Certeau.
} 
material simbólicos através dos quais se compreende, reproduz e transforma a estrutura social" (apud FERREIRA, 1997, p. 23).

Paulo Freire define a cultura como:

[...] o acrescentamento que o homem faz ao mundo que não fez. A cultura como resultado de seu trabalho. Do seu esforço criador e recriador. [...] Descobriria que tanto é cultura o boneco de barro feito pelos artistas, seus irmãos do povo, como cultura também é a obra de um grande escultor, de um grande pintor, de um grande músico, ou de um pensador. Que cultura é a poesia dos poetas letrados de seu país, como também a poesia de seu cancioneiro popular. Que cultura é toda criação humana (FREIRE, 1980, p.109).

Logo, não somos simples resultado das determinações existentes na estrutura social, e sim sujeitos socioculturais, pois participamos da estrutura social, mas nos diferenciamos por meio de nossas dimensões culturais. No mesmo sentido, nossas expressões culturais não estão à margem ou isoladas do todo social.

Neste estudo, o conceito de cultura está desvinculado às determinações biológicas (raciais e definidoras dos padrões civilizacionais), pois acreditamos, da mesma forma que Cuche (2002, p. 137), ser o homem essencialmente um ser cultural. "Toda cultura é um processo permanente de construção, desconstrução e reconstrução".

Segundo Botelho (2001), a cultura pode ser dimensionada em sentido sociológico e antropológico. Conforme a autora, a abrangência de cada definição funda os parâmetros que permitem balizar as estratégias das políticas culturais. Segundo Botelho:

Na dimensão antropológica, a cultura se produz através da interação social dos indivíduos, que elaboram seus modos de pensar e sentir, constroem seus valores, manejam suas identidades e diferenças e estabelecem suas rotinas. Desta forma, cada indivíduo ergue à sua volta, e em função de determinações de tipo diverso, pequenos mundos de sentido que lhe permitem uma relativa estabilidade (BOTELHO, 2001, p. $3)$.

Por sua vez, para a autora, a dimensão sociológica não se constitui no plano do cotidiano, referindo-se a um circuito socialmente organizado, tangível e que permite visibilidade. "Estimula, por diversos meios, a produção, a circulação e o consumo dos 
bens simbólicos". (BOTELHO, 2001, p. 5). Afirma que a dimensão sociológica é a que acaba se favorecendo das políticas públicas.

Optamos, todavia, por trabalhar a cultura em sua perspectiva antropológica historicamente contextualizada, sem deixar de considerar sua dimensão sociológica. Isto é, como todas as expressões do modo de vida dos homens, relativas ao lugar ocupado na estrutura social em dado contexto histórico. A abordagem parte de um conceito dinâmico e histórico da cultura, em processo contínuo de construção cotidiana das relações sociais e como possibilidade de transformação social.

Defendemos que a cultura está presente em todos os aspectos da vida da sociedade e os planos de desenvolvimento são completos quando englobam esse modo de entendê-la.

\section{Cultura popular: estratégia de vivência}

O termo cultura popular, segundo Ferreira (1997, p. 29), apresenta-se “[...] ambíguo e limitado para dar conta da complexidade do universo compreendido nesta realidade". De acordo com a autora e com Cuche (2002), a cultura popular é a cultura de grupos sociais subalternos, entendida como instrumento de contestação. Também podemos considerá-la “[...] como um conjunto de 'maneiras de viver com' a dominação, ou, mais ainda, como um modo de resistência sistemática à dominação" (CUCHE, 2002, p. 150).

Chauí (1996), a partir dos estudos de Thompson e Gramsci, trata a cultura popular como inclusa no "processo global" de uma determinada sociedade e contexto histórico. Porém, existem outras definições possíveis que são contrárias a essa relação dinâmica entre cultura popular e sociedade.

Conforme Chauí (2006), há uma concepção derivada do Romantismo do século XIX, afirmando que cultura popular é a cultura do "povo bom, verdadeiro e justo". Concepção que assinala a busca por universalizar a cultura popular por meio do nacionalismo, transformando-a em "verdadeira cultura nacional". Neste sentido, a cultura popular seria igual primitivismo, comunitarismo, purismo e tradição de uma nação, estando isolada e/ou à parte da dinâmica social. 
Outra definição possível constituiu-se quando da llustração francesa do século XVIII. Esta leitura considera cultura popular "o resíduo de tradição, misto de superstição e ignorância" e algo a ser superado pela civilização e progresso. Logo, a cultura do povo deveria ser corrigida pela educação, propondo sua desaparição por meio da educação formal a ser realizada pelo Estado modernizador e civilizador.

Uma terceira interpretação sobre a cultura popular surgiu do populismo do século $\mathrm{XX}$, misturando as concepções romântica e iluminista; da primeira, sustenta a visão de que a cultura feita pelo povo é "boa e verdadeira"; da segunda, a ideia de que a cultura popular tende a ser tradicional e atrasada com relação a seu tempo, precisando, para se atualizar, de uma ação pedagógica, realizada pelo Estado ou por uma vanguarda política. A partir dessa concepção, uma liderança deveria levar a "consciência correta" para o povo, tornando a cultura popular revolucionária (na perspectiva das vanguardas de esquerda) ou um sustentáculo do Estado (na perspectiva do populismo de direita) (CHAUI, 2006, p. 133).

No entanto, assim como Chauí (2006), divergimos dessas concepções de cultura popular. Compreendemos a cultura do povo em constante e dinâmica interação com a estrutura social e não como algo à margem e/ou isolado que deva ser superado por um suposto progresso.

Ao mesmo tempo, ao vincularmos cultura popular com a idéia de povo, pensamos como Gáudio (1982), ou seja, a cultura popular, por ser do povo, “[...] não é imediatamente libertadora, já que o fato de algo estar no povo não significa necessariamente que é do povo" (GÁUDIO, 1982, p. 113).

A cultura do povo, por vezes, resiste à ideologia dos grupos no poder, mas também é influenciada e incorpora valores relativos aos interesses das classes dominantes. Desta maneira, o termo popular deriva de povo e é relativo às estratégias de vivências das camadas populares. Por isso, é pertinente analisarmos o conceito de povo para compreendermos a construção da cultura popular.

Para Canclini (1998, p. 208), “[...] o povo interessa como legitimador da hegemonia burguesa, mas incomoda como lugar do inculto por tudo aquilo que lhe falta".

De acordo com Chauí, o povo é um conjunto de pessoas que possuem identicidades. A autora explica que "há, pois, o povo como generalidade política", isto é, 
uma idéia de povo como "unidade jurídica dos cidadãos definidos pela lei". No entanto, podemos definir "o povo como particularidade social, os "pobres"” (CHAUI, 1996, p. 17). Nos dois casos, as identidades em comum norteiam o conceito.

Segundo Ferreira (1997, p. 29), o povo pode ser definido "[...] a partir de categorias de classe, como o conjunto das classes subalternas e instrumentais que existem em todos os tipos de sociedade atuais". Contudo, de acordo com Thompson (1981), na definição de uma classe ou grupo social é necessário levar em conta, além do lugar ocupado na estrutura social (sujeito social), a experiência cotidianamente vivenciada e expressa por meio da cultura. Definição utilizada também por Michel de Certeau (1994).

Compreender cultura popular significa, então, perceber que existem mecanismos de dominação simbólica, cujo objetivo é tornar aceitáveis, pelos próprios dominados, as representações e os modos de consumo que qualificam (ou antes desqualificam) sua cultura como inferior e ilegítima e, de outro lado, as lógicas específicas em funcionamento nos usos e nos modos de apropriação do que é imposto.

Porém, como analisam Thompson (1981), Gramsci (1999), Chauí (1996, 2006), Certeau (1994) e Ferreira (1997), o povo não fica passivo em relação às imposições culturais do Estado e da indústria cultural. Por isso, cultura popular é a cultura realizada pelo povo num processo contraditório de reelaboração cultural e de continuação identitária.

Segundo Michel de Certeau (apud CUCHE, 2002, p. 150) a cultura popular é construída no cotidiano, nas atividades "[...] ao mesmo tempo banais e renovadas a cada dia". No mesmo sentido, Ferreira $(1997$, p. 31$)$ entende que a cultura popular se expressa no dia-a-dia, "[...] no espaço e no tempo da cotidianidade das classes subalternas, nas suas condições de luta pela vida, através dos processos de adaptação e ressignificação dos quadros dados pelo sistema".

Outro conceito fundamental para pensarmos a importância da cultura na compreensão da dinâmica social é o de resistência sociocultural. Resistência esta formada pelas expressões populares cotidianas (música, crença, formas de trabalho, alimentação e outros) resultantes das experiências de recusa e (re)elaboração vivenciadas pelo povo.

A resistência parte de um desejo de emancipação. Logo, a cultura popular pode configurar-se como um modo de resistência quando a entendemos: 
[...] como expressão dos dominados, buscando as formas pelas quais a cultura dominante é aceita, interiorizada, reproduzida e transformada, tanto quanto as formas pelas quais é recusada, negada e afastada, implícita ou explicitamente, pelos dominados (CHAUÍ, 1996, p. 24).

Cabe aqui a reflexão sobre o fato de nossa formação histórica ser marcada por processos de escravização e "negação do outro" e de sua alteridade. Processos que também ocorrem "no plano das representações e no imaginário social". (CANDAU, 2002, p. 126). Nesta direção, o debate sobre cultura, especialmente cultura popular, da maneira adotada neste trabalho, coloca-nos diante de sujeitos históricos e de instrumentos de resistência sociocultural por eles utilizados, afirmando suas identidades, ainda que numa "[...] situação de relações de poder assimétricas, de subordinação e acentuada exclusão".

Mesmo com o histórico combate e tentativas de incorporação das vivências sociais e culturais populares por parte dos grupos no poder, o povo assinala que as pessoas não são apenas receptoras passivas da manipulação das classes dominantes, mas sujeitos do processo cultural e social, dialogando, negociando e construindo suas vivências e significados, dando identidade aos espaços e "[...] lutando para fazer com que nos sintamos em casa neste mundo, mesmo que os lares que construímos, a rua moderna, o espírito moderno continuem a desmanchar no ar" (BERMAN, 1996, p. 330).

\section{Cultura como prática de cidadania}

A cultura, embora de grande importância como possibilidade de exercício da cidadania, comumente é tratada em plano secundário nos debates do governo ou das políticas públicas. "Os orçamentos públicos são reveladores: o do Ministério da Cultura é de 0,6\% da União, o do governo do Estado de São Paulo situa-se em torno de 0,4\% e o da maioria dos municípios brasileiros que têm essa rubrica não ultrapassa os 2\%" (MOREIRA; FARIA, 2005, p. 10).

No senso comum, entende-se que há necessidades materiais vitais não atendidas que merecem destaque, enquanto a questão cultural é percebida como algo supérfluo ou suplementar. Além disso, muitas vezes, a cultura é concebida apenas como mercadoria ou negócio que pode levar visibilidade para a marca de um produto ou imagem de uma 
instituição. “Não há praticamente nenhuma atividade cultural que não seja patrocinada, e o patrocínio transforma-se em marca" (OLIVEIRA, 2005, p. 18).

Contudo, acreditamos que a cultura é tão importante quanto a educação e a saúde, por exemplo. Nesse particular, valemo-nos de Moreira e Faria $(2005$, p. 9), que enfatizam: “[...] não é mais possível pensar na mudança social de qualquer país, localidade ou mesmo do planeta sem considerarmos as realidades culturais".

Portanto, as políticas públicas deveriam levar em conta que sociedade e cultura não estão isoladas e precisam ser trabalhadas de maneira integrada. Pensamos a política pública, embora frequentemente seja ela entendida como "política pobre para o pobre" (MARTINELLI, 1998, p. 144), como um instrumento fundamental na efetivação de direitos.

Um governo que não reconhece e valoriza a pluralidade de seus cidadãos, as diferentes realidades locais e a riqueza cultural presente nos diversos territórios que compõem bairros, cidades ou estados, certamente direciona suas ações a uma pequena parcela da população e favorece a cultura hegemônica que tende a homogeneizar identidades e expressões.

Segundo Ferreira (1997, p. 31), "[...] a diferença entre as classes e grupos sociais não é apenas econômica. Mas é o resultado da participação diferenciada na reprodução material-simbólica da sociedade". Logo, a cultura pode ser percebida como elemento essencial para o desenvolvimento humano e social, o que significa dizer que a implantação de políticas públicas não deve estar focada exclusivamente na economia, mas que garanta o fortalecimento das identidades, a preservação da cultura local e a valorização dos distintos saberes populares.

Há que se pensar num alargamento do conceito de cultura para as propostas acontecerem numa perspectiva intersetorial, ou seja, para que haja articulação entre as diversas políticas públicas da região, de modo a não permanecer a cultura como algo isolado ou suplementar.

Bourguignon (2001) corrobora com essa defesa ao explicar que:

Tradicionalmente, as políticas públicas básicas (educação, assistência social, saúde, habitação, cultura, lazer, trabalho, etc.) são setoriais e desarticuladas, respondendo a uma gestão com características centralizadoras, hierárquicas, deixando prevalecer práticas na área social que não geram a promoção humana (BOURGUIGNON, 2001, p. 2). 
Por entendermos cultura como todas as manifestações do homem relativas à práxis social e, da mesma forma que Botelho e Fiore (2005, p. 2), “[...] como o conjunto de práticas e atitudes que têm uma incidência sobre a capacidade do homem de se exprimir, de se situar no mundo, de criar seu entorno e de se comunicar, já que a vida cultural do indivíduo comporta também atitudes em diferentes períodos de sua vida cotidiana", pensamos as políticas públicas no âmbito cultural não apenas ligadas às atividades legitimadas socialmente como culturais, como ir ao teatro ou ao cinema e frequentar museus ou bibliotecas, mas também àquelas relacionadas ao dia a dia dos habitantes da cidade. Tampouco a pensamos como forma de compensar necessidades ou carências, mas como garantia de condições de cidadania.

De acordo com Souza (1997, p. 23):

Não se pode pretender impor uma cultura que não tenha ligação alguma com a vida das pessoas, e achar que assim está garantindo o direito à cultura. Apresentar eventos a preços populares é só um aspecto do direito à cultura e não garante o exercício da cultura como prática de cidadania.

Para que a discussão sobre políticas públicas não seja esvaziada de sentido, faz-se fundamental a apropriação de cultura como um direito de todos os cidadãos. "Afirmar a cultura como um direito é opor-se à política neoliberal, que abandona a garantia dos direitos, transformando-os em serviços vendidos e comprados no mercado e, portanto, em privilégios de classe" (CHAUI, 2006, p. 138).

$\mathrm{Na}$ sociedade capitalista neoliberal e globalizada em que estamos inseridos, segundo Martins, o modo de produção das ideias marca o senso comum e o conhecimento científico a serviço da produção de mercadorias nas condições de exploração e coisificação das pessoas e das relações sociais. Não é, portanto, somente a forma de pensar necessária à reprodução e à reelaboração das bases ideológicas e sociais de sustentação do sistema capitalista, mas o processo de destituir o outro de subjetividade e entendê-lo como objeto. "Os sujeitos misturam-se aos objetos, sem distinção entre uns e outros" (MARTINS, 1978, p. 12), o que expressa as relações vigentes na sociedade. 
São produtos dessas relações, que produzem e reproduzem a desigualdade no plano social, político, econômico e cultural, definindo para os pobres um lugar na sociedade. Um lugar onde são desqualificados por suas crenças, seu modo de expressar-se e seu comportamento social, sinais de 'qualidades negativas' e indesejáveis que lhes são conferidas por sua procedência de classe, por sua condição social. Este lugar tem contornos ligados à própria trama social que gera a desigualdade e que se expressa não apenas em circunstâncias econômicas, sociais e políticas, mas também nos valores culturais das classes subalternas e de seus interlocutores na vida social (YAZBEK, 2001, p. 34).

Segundo a autora, vivenciamos a crise das políticas sociais, seu reordenamento e sua subordinação às políticas econômicas, as restrições do gasto público e sua perspectiva privatizadora, a despolitização do reconhecimento da questão social como expressão das relações de classe. Entendemos que enquanto o econômico for preponderante em relação ao social, estaremos diante de injustiças sociais. Assim, como podemos pensar em construir e consolidar direitos num mundo globalizado, desigual e injusto como esse? ${ }^{5}$

É essencial acreditarmos, como destaca Martinelli a partir dos estudos de Marx, que na mesma sociedade que oprime é possível também descobrir os caminhos para a libertação. No entanto, nossa intenção aqui não é oferecer soluções para um debate tão complexo, mas apontar reflexões sobre o assunto.

Vale considerar que, ao discutirmos a defesa de direitos, devemos ter em mente o princípio da dignidade humana, ou seja, de busca pela igualdade, porém não a igualdade de pensamento e comportamento únicos ou de uma ausência de conflitos, mas de reconhecimento e respeito à diversidade. Conforme Boaventura de Sousa Santos (2002, p. 11), "[...] as pessoas e os grupos sociais têm o direito a ser iguais quando a diferença os inferioriza, e o direito a ser diferentes quando a igualdade os descaracteriza".

Concordamos com Martinelli ao assinalar a urgência de reinventar o conceito de cidadania. "É dramático reconhecer que estamos considerando cidadania como faixa etária, como poder de compra, como contrato de trabalho, como carteira assinada". (MARTINELLI, 1998, p. 142). Ou, ainda, simplesmente, como o direito ao voto. Sabemos,

\footnotetext{
${ }^{5}$ Inquietação compartilhada por trabalhadores sociais do mundo todo, haja vista a temática da 19a Conferência Mundial de Serviço Social (da qual participei), realizada de 16 a 19 de agosto de 2008, em Salvador, BA - "O desafio de concretizar direitos numa sociedade globalizada e desigual".
} 
entretanto, que seu significado é bem mais abrangente, bem mais desafiador e bem mais urgente de ser atendido e alcançado.

A cidadania deve ser entendida como direito à vida, em sua plenitude. Trata-se não apenas de atendimento às necessidades básicas, mas do acesso a todos os níveis de existência, a partir de uma construção coletiva. Logo, partimos da ampliação da ideia de direitos e de cidadania para além da perspectiva marshaliana.

Para que a dignidade humana seja efetiva, há de se respeitar todos os direitos humanos, e os direitos culturais não fogem a esta regra. Chauí afirma que:

[...] a cultura não se reduz ao supérfluo, ao entretenimento, aos padrões do mercado, à oficialidade doutrinária (que é ideologia), mas se realiza como direito de todos os cidadãos, direito a partir do qual a divisão social das classes ou a luta de classes possa manifestar-se e ser trabalhada porque, no exercício do direito à cultura, os cidadãos, como sujeitos sociais e políticos, se diferenciam, entram em conflito, comunicam e trocam suas experiências, recusam formas de cultura, criam outras e movem todo o processo cultural (CHAUI, 2006, p. 138).

A Constituição Federal de 1988 classifica a cultura como direito do cidadão, em seus artigos 215 e 216. Ainda, em seus artigos 23 e 24, destaca ser competência do Estado "proporcionar os meios de acesso à cultura [...]" e a "proteção ao patrimônio histórico, cultural, artístico, turístico e paisagístico".

Também o artigo 27 da Declaração dos Direitos Humanos assegura que: "Toda pessoa tem o direito de participar livremente da vida cultural da comunidade, de fruir as artes e de participar do progresso científico e de seus benefícios" (UNESCO, 2002).

Além disso, a Declaração Universal sobre a Diversidade Cultural da UNESCO, em seus artigos 4, 5 e 6, garante o exercício da cidadania a partir da cultura quando destaca:

Artigo 4 - Os direitos humanos, garantias da diversidade cultural A defesa da diversidade cultural é um imperativo ético, inseparável do respeito à dignidade humana. Ela implica o compromisso de respeitar os direitos humanos e as liberdades fundamentais, em particular os direitos das pessoas que pertencem a minorias e os dos povos autóctones. [...] Artigo 5 - Os direitos culturais, marco propício da diversidade cultural Os direitos culturais são parte integrante dos direitos humanos, que são universais, indissociáveis e interdependentes. [...] Toda pessoa deve, assim, poder expressar-se, criar e difundir suas obras na língua que deseje e, em particular, na sua língua materna; toda pessoa tem direito 
a uma educação e uma formação de qualidade que respeite plenamente sua identidade cultural; toda pessoa deve participar na vida cultural que escolha e exercer suas próprias práticas culturais, dentro dos limites que impõe o respeito aos direitos humanos e às liberdades fundamentais.

Artigo 6 - Rumo a uma diversidade cultural acessível a todos

Enquanto se garanta a livre circulação das idéias mediante a palavra e a imagem, deve-se cuidar para que todas as culturas possam se expressar e se fazer conhecidas. A liberdade de expressão, o pluralismo dos meios de comunicação, o multilingüismo, a igualdade de acesso às expressões artísticas, ao conhecimento científico e tecnológico - inclusive em formato digital - e a possibilidade, para todas as culturas, de estar presentes nos meios de expressão e difusão, são garantias da diversidade cultural. (UNESCO, 2002).

De acordo com Gohn (2005, p. 43), “[...] o reconhecimento e a realização ampla de todos estes direitos (leia-se direitos culturais) supõe, certamente, indivíduos cidadãos com acesso e direito a viver em condições condignas de existência".

A possibilidade de mudança acontece na medida em que esses indivíduos passam a se reconhecer como sujeitos de direitos, com voz, com poder, partícipes do processo de construção dos diferentes territórios, criadores e transformadores de realidades.

\title{
Considerações finais
}

\author{
"Mas se é verdade que a paciência \\ dos conceitos é grande, \\ a paciência da utopia é infinita." \\ Boaventura de Sousa Santos
}

Acreditamos que o presente estudo não se esgota aqui, haja vista a complexidade dos conceitos trabalhados e a importância de seu debate para o exercício da cidadania e de sua aplicação nas políticas públicas.

A partir das obras analisadas, especialmente após o estudo de Canclini (1998), Chauí (1996; 2006), Cuche (2002), Freire (1980), Moreira e Faria (2005), afastamo-nos do conceito de cultura relacionado à superioridade e inferioridade racial e civilizacional para entendermos a cultura como toda criação humana, princípio fundamental para o desenvolvimento humano e social, além de um instrumento de transformação social e de resistência sociocultural.

Concluímos que este ensaio contribui para a reflexão sobre o reconhecimento e a importância das manifestações culturais populares no planejamento e formulação de 
políticas públicas e da cultura como direito de todos os cidadãos, elemento essencial para o exercício pleno da cidadania.

Portanto, defendemos o alargamento do conceito de cultura; a cidadania para além dos direitos civis, políticos e sociais, ou seja, o direito à vida, em sua plenitude; o reconhecimento e a valorização da diversidade sociocultural nos diversos territórios brasileiros, refutando, em nome da diferença, a justificativa para a desigualdade. Assim, prosseguimos na luta em prol de uma sociedade democrática e socialmente justa.

\section{Referências}

BERMAN, M. Tudo que é sólido desmancha no ar: a aventura da modernidade. São Paulo: Companhia das Letras, 1996.

BOTELHO, I. As dimensões da cultura e o lugar das políticas públicas. São Paulo em perspectiva, São Paulo: Revista da Fundação SEADE, 2001.

BOTELHO, I.; FIORE, M. O uso do tempo livre e as práticas culturais na região metropolitana de São Paulo. CEBRAP, 2005. Relatório da Primeira Etapa da Pesquisa.

BOURGUIGNON, J. A. Concepção de rede intersetorial. 2001. Disponível em: <http://www.uepg.br/nupes/intersetor.htm>. Acesso em 24 jan. 2009.

BRASIL. Constituição Federativa do Brasil. Brasília: Senado Federal, 1988.

CANCLINI, N. G. Culturas híbridas. São Paulo: EDUSP, 1998.

CANDAU, V. M. F. Sociedade, cotidiano escolar e cultura(s): uma aproximação. 2002. Disponível em: <http://www.scielo.br/pdf/es/v23n79/10852.pdf>. Acesso em 24 jun. 2008.

CERTEAU, M. de. A invenção do cotidiano. Petrópolis: Vozes, 1994.

CHAUI, M. Cidadania cultural: o direito à cultura. São Paulo: Fundação Perseu Abramo, 2006.

. Conformismo e resistência: aspectos da cultura popular no Brasil. São Paulo: Brasiliense, 1996.

CHOAY, F. O reino do urbano e a morte da cidade. Revista Projeto História, São Paulo, n. 18, p. 67-89, maio 1999.

CUCHE, D. A noção de cultura nas ciências sociais. Bauru: EDUSC, 2002.

DICIONÁRIO Houaiss da Língua Portuguesa. Disponível em: <http://houaiss.uol.com.br>. 
Acesso em 10 dez. 2008.

FERREIRA, M. N. Cultura subalterna e o neoliberalismo: a encruzilhada da América Latina. São Paulo: CELAC: ECA/USP, 1997.

FOUCAULT, M. Microfísica do poder. Rio de Janeiro: Graal, 1985.

FREIRE, P. Educação como prática da liberdade. Rio de Janeiro: Paz e Terra, 1980.

GÁUDIO, M. O. M. Cultura popular e serviço social. Revista Serviço Social \& Sociedade, São Paulo, n. 8, 1982.

GOHN, M. da G. O protagonismo da sociedade civil: movimentos sociais, ONGs e redes solidárias. São Paulo, Cortez, 2005.

GRAMSCl, A. Cadernos do cárcere. São Paulo: Civilização Brasileira, 1999. v. 1.

HOBSBAWM, E. Era dos extremos: o breve século XX, 1914-1991. São Paulo: Cia. das Letras, 1995.

KARL, F. R. George Eliot: a voz de um século. Rio de Janeiro: Record, 1995.

MARTINELLI, M. L. O Serviço social na transição para o próximo milênio: desafios e perspectivas. Serviço Social \& Sociedade, São Paulo, n. 57, 1998.

MARTINS, José de Souza. O modo capitalista de pensar. São Paulo: Hucitec, 1978.

MOREIRA, A. J.; FARIA, H. Cultura e governança: um olhar transversal de futuro para o município. In: FARIA, H.; MOREIRA, A. J.; VERSOLATO, F. (Org.). Você quer um bom conselho? Conselhos municipais de cultura e cidadania cultural. São Paulo: Pólis, 2005. p. 9-18

OLIVEIRA, F. O capital contra a democracia. In: TEIXEIRA, A. C. C. (Org.). Os sentidos da democracia e da participação. São Paulo: Pólis, 2005.

PAULO NETTO, J.; CARVALHO, M. do C. B. de. Cotidiano: conhecimento e crítica. São Paulo: Cortez, 2007.

SANTOS, B. de S. As tensões da modernidade. 2002. Disponível em: <http://www.forumsocialmundial.org.br>. Acesso em: 15 fev. 2009.

SCHWARCZ, L. M. O espetáculo das raças. Cientistas, instituições e questão racial no Brasil: 1870-1930. São Paulo: Cia. das Letras, 1993.

SOUZA, V. São Paulo: diversidade cultural e discurso oficial. In: FARIA, H.; SOUZA, V. (Org.). Cidadania cultural: leituras de uma política pública. São Paulo: Pólis, 1997. p. 23

THOMPSON, E. P. Miséria da teoria. Rio de Janeiro: Zahar, 1981.

UNESCO. Declaração universal sobre a diversidade cultural. 2002. Disponível em: 
<http://unesdoc.unesco.org/images/0012/001271/127160por.pdf >. Acesso em: 15 fev. 2009.

YAZBEK, M. C. Pobreza e exclusão social: expressões da questão social no Brasil. Temporalis, Brasília, ano 2, n. 3, jan./jun. 2001. 